\title{
Prognostic impact of progesterone receptor status combined with body mass index in breast cancer patients treated with adjuvant aromatase inhibitor
}

\author{
MASAHIRO OHARA $^{1}$, ETSUSHI AKIMOTO ${ }^{1}$, MIDORI NOMA ${ }^{1}$, KAZUO MATSUURA ${ }^{1}$, \\ MIHOKO DOI $^{2}$, NAOKI KAGAWA ${ }^{3}$ and TOSHIYUKI ITAMOTO ${ }^{1}$ \\ Departments of ${ }^{1}$ Breast Surgery and ${ }^{2}$ Clinical Oncology, Hiroshima Prefectural Hospital, \\ Hiroshima 734-8530; ${ }^{3}$ Kagawa Breast Clinic, Hiroshima 730-0029, Japan
}

Received October 9, 2014; Accepted August 5, 2015

DOI: 10.3892/ol.2015.3655

\begin{abstract}
Aromatase inhibitors have played a central role in endocrine therapy for the treatment of estrogen receptor (ER)-positive breast cancer in postmenopausal patients. However, prognostic factors for recurrence following such treatment have not been identified. The current study aimed to validate the prognostic value of endocrine-related progesterone receptor $(\mathrm{PgR})$ status combined with body mass index (BMI). Among 659 consecutive patients with primary breast cancer who underwent curative surgery between 2002 and 2012, 184 postmenopausal patients with ER-positive (ER+) and human epidermal growth factor receptor type 2-negative (HER2-) breast cancer who were treated with adjuvant aromatase inhibitor therapy were assessed. The patients were assigned to groups based on BMI, according to the WHO cut-off value: $\geq 25 \mathrm{~kg} / \mathrm{m}^{2}$ (high, H) or $<25 \mathrm{~kg} / \mathrm{m}^{2}$ (low, L). Positive nodal status, negative PgR status, BMI-H and a high Ki-67 labeling index ( $\geq 20 \%$ ) were found to be significantly associated with a short recurrence-free interval (RFI) upon univariate analysis $(\mathrm{P}=0.048,0.007,0.027$, and 0.012 , respectively). The patients were further grouped based on their combined PgR/BMI status. The RFI was significantly shorter in the PgR- and/or BMI-H group compared with that of the PgR+/BMI-L group $(\mathrm{P}=0.012)$. Multivariate analysis revealed PgR- tumors and/or BMI-H and positive nodal status to be independent prognostic factors $(\mathrm{P}=0.012$
\end{abstract}

Correspondence to: Dr Masahiro Ohara, Department of Breast Surgery, Hiroshima Prefectural Hospital, 1-5-54 Ujina-Kanda, Minami, Hiroshima 734-8530, Japan

E-mail: oharamas@hotmail.com

Abbreviations: BMI, body mass index; CI, confidence interval; ER, estrogen receptor; HER2, human epidermal growth factor receptor type 2; HR, hazard ratio; PgR, progesterone receptor; RFI, recurrence-free interval

Key words: breast cancer, body mass index, progesterone receptor, aromatase inhibitor and 0.020 , respectively). The present findings indicate that $\mathrm{PgR} / \mathrm{BMI}$ status may serve as a practical tool in the management of ER+ and HER2- breast cancer in patients treated with adjuvant aromatase inhibitors.

\section{Introduction}

Aromatase inhibitors have been widely administered as adjuvant treatment for hormone receptor-positive breast cancer in postmenopausal women. The results of recent clinical trials have demonstrated that third-generation aromatase inhibitors, including anastrozole, letrozole and exemestane, are more effective than tamoxifen in treating early stage or metastatic breast cancer in postmenopausal women (1). Thus, aromatase inhibitors are now considered to be the gold standard of endocrine therapy for such patients in adjuvant and metastatic settings $(2,3)$. Characterization of the risk of recurrence for patients who receive aromatase inhibitors is important for selecting appropriate treatment. However, factors that can predict the outcomes of aromatase inhibitor treatment remain unknown.

A number of studies have investigated tumor biomarkers that indicated differential benefit from aromatase inhibitors versus tamoxifen in patients with early breast cancer (4-6). Such biomarkers included the conventional factors, estrogen receptor (ER), progesterone receptor $(\mathrm{PgR})$, human epidermal growth factor receptor type 2 (HER2) and Ki-67, and did not identify patients who derived a differential relative benefit from aromatase inhibitors over tamoxifen. Expression of the PgR gene is thought to largely depend on an intact ER signaling pathway, and the expression of $\mathrm{PgR}$ is associated with endocrine responsiveness (7). Low PgR expression was found to be associated with a poor prognosis in patients treated with adjuvant tamoxifen therapy (8). However, the prognostic significance of $\mathrm{PgR}$ in patients treated with adjuvant aromatase inhibitors has remained unclear.

The risk of breast cancer risk among postmenopausal women is positively associated with higher circulating concentrations of estrogen. Obese women have higher circulating estradiol levels as adipose tissue is an important source of estrogens in postmenopausal women (9-11). As obesity 
is associated with increased adipose tissue and aromatase activity, aromatase inhibitors may be less effective in women who are overweight or obese.

The $\sim 15 \%$ of breast cancer patients with overexpressed HER 2 are treated with trastuzumab, a monoclonal antibody targeting HER2, combined with adjuvant chemotherapy (12). Conversely, the selection criteria of adjuvant treatment in patients with the ER+/HER2- subtype is particularly difficult to define. Patients who are at high risk for recurrence need to be distinguished from those at low risk, for whom adjuvant aromatase inhibitors may be sufficient (4-6).

Based on this background, we postulated that PgR/body mass index (BMI) status would affect the outcomes of adjuvant aromatase inhibitor therapy in postmenopausal women, as $\mathrm{PgR}$ is an endocrine-related tumor factor and $\mathrm{BMI}$ is an endocrine-related factor. The aim of the current study was to attempt to classify patients with ER+/HER2- breast cancer by analyzing the associations between PgR/BMI status and clinicopathological factors, including prognosis.

\section{Patients and methods}

Patients. Between September 2002 and October 2012, 659 consecutive patients with primary breast cancer underwent curative surgery at Hiroshima Prefectural Hospital. Among the 391 postmenopausal patients who had breast cancer while menopausal, 56 who had received preoperative chemotherapy and 118 who were either ER- or HER2+ were excluded from the analysis. In addition, 5 patients who were treated with tamoxifen and 28 who did not undergo endocrine therapy were also excluded. Finally, data derived from 184 postmenopausal patients with a median age of 64 years (range, 50-91 years) and with ER+/HER2- breast cancer treated with aromatase inhibitors were analyzed (Fig. 1). Patients who were considered to be at high risk according to prevalent breast cancer guidelines were administered with chemotherapy (13-18). A total of 4 cycles of doxorubicin $\left(60 \mathrm{mg} / \mathrm{m}^{2}\right)$ and cyclophosphamide $\left(600 \mathrm{mg} / \mathrm{m}^{2}\right)$ every 3 weeks were administered. A total of 4 cycles of docetaxel $\left(75 \mathrm{mg} / \mathrm{m}^{2}\right)$ every 3 weeks were added if the nodal status was positive. BMI was defined as weight $(\mathrm{kg})$ divided by the square of height in meters $\left(\mathrm{kg} / \mathrm{m}^{2}\right)$ at the time of primary breast cancer surgery. The World Health Organization (WHO) cut-off value was applied to assign the patients to high ( $\geq 25 \mathrm{~kg} / \mathrm{m}^{2}$; BMI-H) or low ( $\geq 25 \mathrm{~kg} / \mathrm{m}^{2}$; BMI-H) BMI groups (19). The follow-up period (median, 46.1 months) ended on 31 July, 2013. Demographic and medical data, including age, menopausal status, weight, height, type of breast surgery and history of treatment for breast cancer and endocrine therapy, were collected from medical charts. The institutional review board of Hiroshima Prefectural Hospital approved the study (no. H25-55) and waived the requirement for informed consent from individual patients.

Clinicopathologicalfactors. Clinicopathological factors were determined according to the General Rules for Clinical and Pathological Recording of Breast Cancer, 16th edition (20). Positive ER and PgR status was determined by immunohistochemistry (IHC) and scored according to the Allred system (21). Tumors were defined as HER2+ when IHC scores were 3+ or HER2 amplification ratios (HER2/CEP17) by fluorescence in situ hybridization were $>2.2$. Ki-67 was detected by staining with a MIB1 antibody. Different areas of densely stained lesions were selected under microscopy and >500 cancer cells were assessed to determine Ki-67 expression levels; values were expressed as the percentage of positive cells in each case. Cases with a Ki-67 labeling index $\geq 20 \%$ were defined as positive, whilst cases with an index $<20 \%$ were defined as negative (22). Briefly, tumor specimens were stained using rabbit monoclonal anti-ER antibody (SP1; 790-4324, Ventana Medical Systems, pre-diluted), rabbit monoclonal anti-PgR antibody (1E2; 790-2223, Ventana Medical Systems, pre-diluted), rabbit monoclonal anti-HER2 antibody (4B5; 790-2991, Ventana Medical Systems, prediluted), and mouse monoclonal anti-Ki67 antibody (MIB-1; M7240, Dako, 1:80). IHC staining was performed according to the ultraView Universal DAB Detection Kit (760-500, Ventana Medical Systems) manufacturer's instructions.

Follow-up evaluation. All patients were followed up from the day of surgery. Follow-up care plans included clinical breast and regional lymph node examinations by visual and touch inspection every 3 months and yearly mammograms. Recurrence was defined as any unequivocal occurrence of new cancer foci in a hitherto disease-free patient. The site of the first cancer recurrence and the interval between surgery and recurrence were determined. Recurrence-free intervals (RFI) were calculated as the amount of elapsed time between the date of surgery and that of the first confirmation of cancer recurrence or the last clinical contact attesting to disease-free status.

Statistical analysis. Data are presented as number of patients (with percentages) or as means, unless otherwise stated. Frequencies were compared using the $\chi^{2}$ test for categorical variables, and small samples were assessed using Fisher's exact test. The duration of the RFI was determined using Kaplan-Meier analyses, and differences in RFI were assessed using the log-rank test. Cox's proportional hazards model was used for univariate and multivariate analyses of prognostic values. Multivariate analyses included variables determined to have $\mathrm{P}<0.05$ in the univariate analyses; $\mathrm{P}<0.05$ was considered to indicate statistical significance in all tests. Data were statistically analyzed using SPSS software version 10.5 (SPSS Inc., Chicago, IL, USA) (23).

\section{Results}

Patient's characteristics. Table I shows the clinicopathological characteristics of the 184 patients enrolled in this study. Among these patients, the median age was 64 years (range, 50-91 years), 130 patients $(70.7 \%)$ had pT1 status, $40(21.7 \%)$ had positive nodal status, and $89 \%$ of the tumors were histopathologically diagnosed (by hematoxylin and eosin staining) as invasive ductal carcinoma. Over $80 \%$ of the tumors were $\mathrm{PgR}+(83.7 \%)$, the median Ki-67 labeling index was $16.3 \%$ (range, 0.0-60.0\%) and $53(28.8 \%$ ) patients had received adjuvant chemotherapy. Anastrozole treatment had been administered in 96 (52.2\%) cases, whilst 84 (45.7\%) patients had been treated with letrozole. Fig. 2 shows the distribution 
Table I. Patient's characteristics $(n=184)$.

\begin{tabular}{|c|c|}
\hline Variable & Value \\
\hline Age, years; median (range) & $64.0(50-91)$ \\
\hline Body mass index, kg/m²; median (range) & $23.6(14.6-38.8)$ \\
\hline \multicolumn{2}{|l|}{ Histology, n (\%) } \\
\hline Invasive ductal carcinoma & $164(89.1)$ \\
\hline Invasive lobular carcinoma & $4(2.2)$ \\
\hline Other & $16(8.7)$ \\
\hline \multicolumn{2}{|l|}{ pT stage, n (\%) } \\
\hline $\mathrm{T} 1$ & $130(70.7)$ \\
\hline $\mathrm{T} 2$ & $49(26.6)$ \\
\hline T3 & $1(0.5)$ \\
\hline $\mathrm{T} 4$ & $4(2.2)$ \\
\hline \multicolumn{2}{|l|}{ Nodal status, n (\%) } \\
\hline Negative & $144(78.3)$ \\
\hline Positive & $40(21.7)$ \\
\hline \multicolumn{2}{|l|}{ Nuclear grade, n (\%) } \\
\hline I & $25(13.6)$ \\
\hline II & $132(71.7)$ \\
\hline III & $22(12.0)$ \\
\hline Unknown & $5(2.7)$ \\
\hline \multicolumn{2}{|l|}{ Lymphovascular invasion, n (\%) } \\
\hline Negative & $30(16.3)$ \\
\hline Positive & $154(83.7)$ \\
\hline \multicolumn{2}{|l|}{ Progesterone receptor, n (\%) } \\
\hline Negative & $30(16.3)$ \\
\hline Positive & $154(83.7)$ \\
\hline Ki-67 labeling index, \%; median (range) & $16.3(0.3-60.0)$ \\
\hline \multicolumn{2}{|l|}{ Type of surgery, n (\%) } \\
\hline Breast-conserving surgery & $137(74.5)$ \\
\hline Modified radical mastectomy & $47(25.5)$ \\
\hline \multicolumn{2}{|l|}{ Endocrine therapy, n (\%) } \\
\hline Anastrozole & $96(52.2)$ \\
\hline Letrozole & $84(45.7)$ \\
\hline Exemestane & $4(2.1)$ \\
\hline \multicolumn{2}{|l|}{ Chemotherapy, n (\%) } \\
\hline Yes & $53(28.8)$ \\
\hline No & $131(71.2)$ \\
\hline \multicolumn{2}{|l|}{ Recurrence, n (\%) } \\
\hline Local recurrence & $5(2.7)$ \\
\hline Distant metastasis & $11(6.0)$ \\
\hline
\end{tabular}

of patients according to BMI (median, $23.6 \mathrm{~kg} / \mathrm{m}^{2}$; range, 14.6 $38.8 \mathrm{~kg} / \mathrm{m}^{2}$ ). Two thirds of these patients were underweight or of normal weight $(n=120)$, and one third was overweight $(n=52)$ or obese $(n=12)$ (Fig. 2).

Regression analyses of RFI. Breast cancer recurred in 16 patients during the follow-up period. The variables included in the univariate analysis of RFI in the 184 patients were BMI, tumor size, nodal status, nuclear grade, lymphovascular inva-

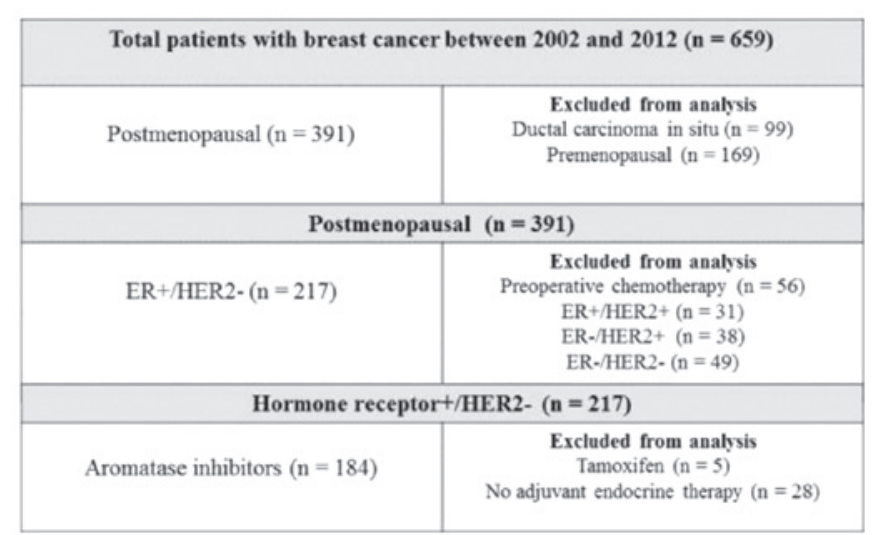

Figure 1. Flow diagram of study participants. ER, estrogen receptor; HER2, human epidermal growth factor receptor type 2 .

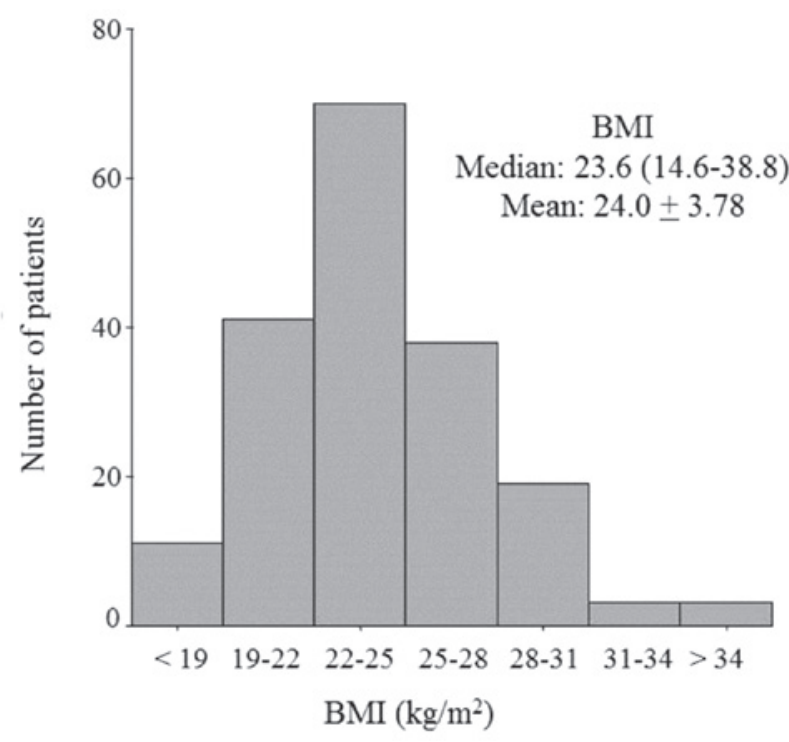

Figure 2. Distribution of body mass index (BMI).

sion status, PgR status, Ki-67 labeling index and chemotherapy. A high BMI, positive nodal status, negative PgR status and high Ki-67 labeling index were significantly associated with a short RFI $(\mathrm{P}=0.048,0.007,0.027$, and 0.012 , respectively).. Multivariate analysis, which included BMI, nodal status, PgR status and Ki-67 labeling index, identified positive nodal status as an independent prognostic factor for RFI [hazard ratio, 3.27; 95\% confidence interval, 1.20-8.90; $\mathrm{P}=0.020$ ] (Table II).

Impact of PgR/BMI status on clinicopathological factors and prognosis. Considering the mechanism of action of aromatase inhibitors, the impact of PgR/BMI status on prognosis was analyzed. A significantly shorter RFI was observed in patients with PgR-negative tumors and/or BMI-H compared with that of PgR-positive tumors and low BMI (PgR+/BMI-L; P=0.003) (Fig. 3).

Tumors were significantly larger and the Ki-67 labeling index was higher in the 'unfavorable' PgR- or BMI-H group, than in the 'favorable' $\mathrm{PgR}+/ \mathrm{BMI}-\mathrm{L}$ group $(\mathrm{P}=0.024$ and $<0.001$, respectively). Nodal status was not associated with the combined $\mathrm{PgR} / \mathrm{BMI}$ status ( $\mathrm{P}=0.721$; Table III). 
Table II. Univariate and multivariate analyses of recurrence-free interval.

A, Univariate analysis

\begin{tabular}{lccc}
\hline Variable & Value & HR $(95 \%$ CI $)$ & P-value \\
\hline BMI & $\geq 25 \mathrm{~kg} / \mathrm{m}^{2}$ & $2.71(1.01-7.29)$ & 0.048 \\
T stage & $\mathrm{T} 2 / 3 / 4$ & $1.62(0.60-4.35)$ & 0.349 \\
Nodal status & Positive & $3.84(1.44-10.25)$ & 0.007 \\
Nuclear grade & III & $2.11(0.60-7.48)$ & 0.248 \\
Lymphovascular invasion & Positive & $26.9(0.08-8837.97)$ & 0.265 \\
Progesterone receptor status & Negative & $3.13(1.13-8.65)$ & 0.027 \\
Ki-67 labeling index & $\geq 20 \%$ & $4.24(1.37-13.20)$ & 0.012 \\
Chemotherapy & Yes & $1.57(0.5714 .33)$ & 0.381 \\
\hline
\end{tabular}

B, Multivariate analysis

\begin{tabular}{lccr}
\hline Variable & Value & HR (95\% CI) & P-value \\
\hline BMI & $\geq 25 \mathrm{~kg} / \mathrm{m}^{2}$ & $1.04(0.90-1.19)$ & 0.610 \\
Nodal status & Positive & $3.27(1.20-8.90)$ & 0.020 \\
Progesterone receptor status & Negative & $2.62(0.88-7.84)$ & 0.085 \\
Ki-67 labeling index & $\geq 20 \%$ & $0.29(0.83-9.33)$ & 0.097 \\
\hline
\end{tabular}

BMI, body mass index; CI, confidence interval; HR, hazard ratio.

A

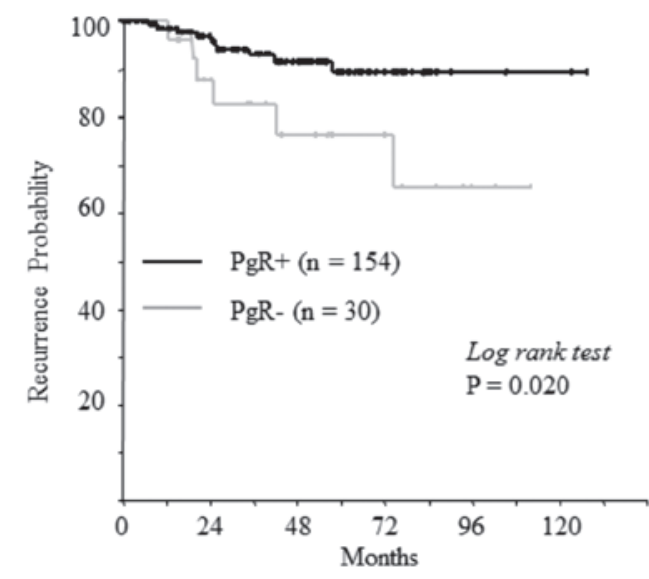

C

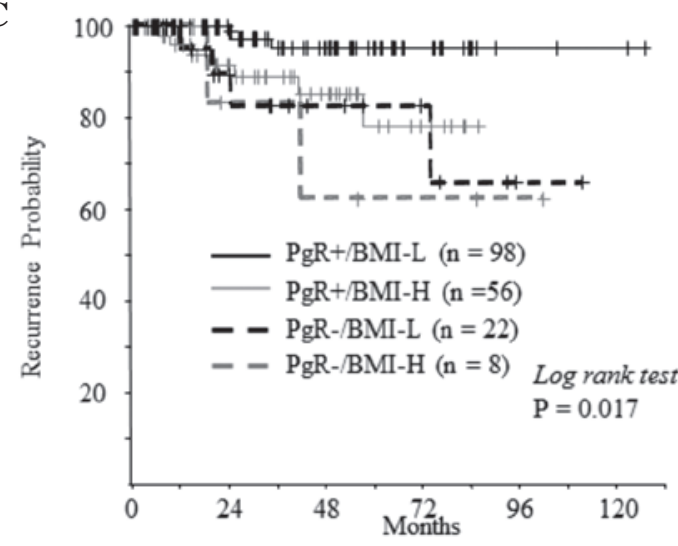

B

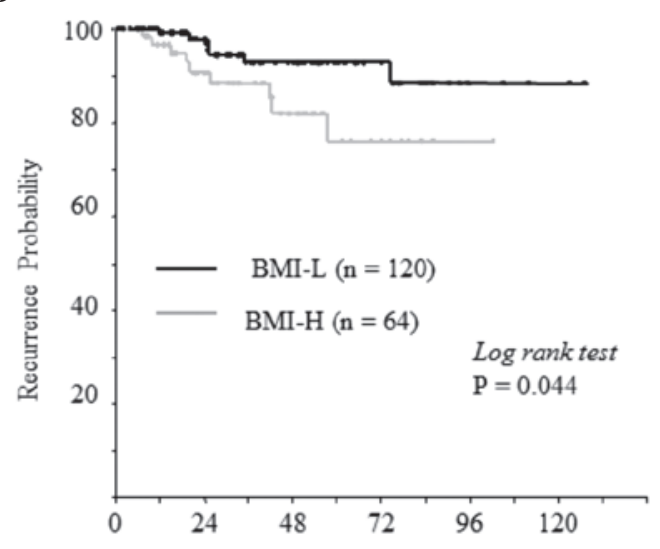

D

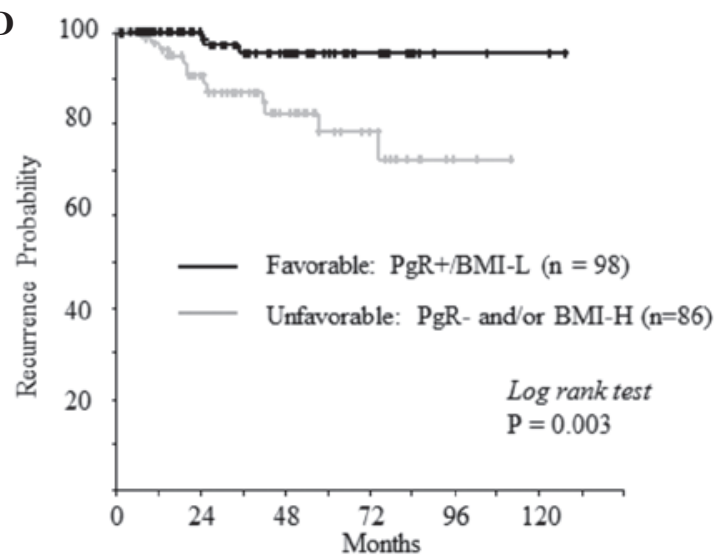

Figure 3. Recurrence-free intervals according to (A) PgR status, (B) BMI, (C) combined PgR and BMI subgroups, (D) combined PgR/BMI status (PgR+/BMI-L vs. PgR- and/or BMI-H) among patients with estrogen receptor-positive/human epidermal growth factor receptor type 2-negative breast cancer after adjuvant therapy with aromatase inhibitors. PgR, progesterone receptor; BMI, body mass index; L, low $\left(<25 \mathrm{~kg} / \mathrm{m}^{2}\right) ; \mathrm{H}, \mathrm{high}\left(\geq 25 \mathrm{~kg} / \mathrm{m}^{2}\right)$. 
Table III. Clinicopathological implications of combined PgR/BMI status in postmenopausal patients with ER+/HER2- breast cancer.

\begin{tabular}{|c|c|c|c|}
\hline Variable & $\begin{array}{l}\mathrm{PgR}+/ \mathrm{BMI}-\mathrm{L} \\
\quad(\mathrm{n}=98)\end{array}$ & $\begin{array}{l}\text { PgR- and/or BMI-H } \\
\qquad(\mathrm{n}=86)\end{array}$ & P-value \\
\hline Age, years; mean \pm SD & $65.7 \pm 8.5$ & $65.2 \pm 8.3$ & 0.705 \\
\hline T stage, $\mathrm{n}(\%)$ & & & 0.024 \\
\hline $\mathrm{T} 1$ & $76(77.6)$ & $53(61.6)$ & \\
\hline $\mathrm{T} 2, \mathrm{~T} 3, \mathrm{~T} 4$ & $22(22.4)$ & $33(38.4)$ & \\
\hline Nodal status, n (\%) & & & 0.721 \\
\hline Negative & $78(79.6)$ & $66(76.7)$ & \\
\hline Positive & $20(20.4)$ & $20(23.3)$ & \\
\hline Nuclear grade, n (\%) & & & 0.113 \\
\hline $\mathrm{I} / \mathrm{II}$ & $87(91.6)$ & $70(83.3)$ & \\
\hline III & $8(8.4)$ & $14(16.7)$ & \\
\hline Lymphovascular invasion, n (\%) & & & 0.239 \\
\hline Negative & $19(19.4)$ & $11(12.8)$ & \\
\hline Positive & $79(80.6)$ & $75(87.2)$ & \\
\hline Ki-67 labeling index,$\%$; mean \pm SD & $16.3 \pm 10.3$ & $23.4 \pm 14.4$ & $<0.001$ \\
\hline Type of surgery, n (\%) & & & 0.503 \\
\hline Breast-conserving surgery & $75(76.5)$ & $62(72.1)$ & \\
\hline Modified radical mastectomy & $23(23.5)$ & $24(27.9)$ & \\
\hline \multicolumn{4}{|l|}{ Endocrine therapy, n (\%) } \\
\hline Anastrozole & $53(54.1)$ & $43(50.0)$ & 0.649 \\
\hline Letrozole & $43(43.9)$ & $41(47.7)$ & \\
\hline Exemestane & $2(2.0)$ & $2(2.4)$ & \\
\hline Chemotherapy, n (\%) & & & 0.516 \\
\hline Yes & $72(73.5)$ & $59(68.6)$ & \\
\hline No & $26(26.5)$ & $86(31.4)$ & \\
\hline Recurrence, n (\%) & & & 1.00 \\
\hline Local recurrence & $1(33.3)$ & $4(30.8)$ & \\
\hline Distant recurrence & $2(66.7)$ & $9(69.2)$ & \\
\hline
\end{tabular}

BMI, body mass index; BMI-L, low body mass index; BMI-H, high body mass index; ER, estrogen receptor; HER2, human epidermal growth factor receptor 2; PgR, progesterone receptor; PgR-, progesterone receptor-negative; PgR+, progesterone receptor-positive.

Table IV. Univariate and multivariate analyses of recurrence-free interval (combined PgR/BMI status).

A, Univariate analysis

\begin{tabular}{lccc}
\hline Variable & Value & HR (95\% CI) & P-value \\
\hline PgR/BMI & PgR- and/or BMI-H & $5.40(1.54-18.91)$ & 0.009 \\
\hline
\end{tabular}

B, Multivariate analysis

\begin{tabular}{lccc}
\hline Variable & Value & HR (95\% CI) & P-value \\
\hline PgR/BMI & PgR- and/or BMI-H & $5.07(1.43-18.00)$ & 0.012 \\
Nodal status & Positive & $3.40(1.22-9.52)$ & 0.020 \\
Ki-67 labeling index & $\geq 20 \%$ & $1.28(0.39-4.25)$ & 0.682 \\
\hline
\end{tabular}

BMI, body mass index; BMI-H, high body mass index; CI, confidence interval; HR, hazard ratio; PgR, progesterone receptor; PgR-, progesterone receptor-negative. 
Multivariate analysis of combined PgR/BMI status, nodal status and the $\mathrm{Ki}-67$ labeling index using the Cox proportional hazards regression model identified PgR- or BMI-H and positive nodal status as independent prognostic factors $(\mathrm{P}=0.012$ and 0.020 , respectively) (Table IV).

\section{Discussion}

The current study described a series of 184 postmenopausal patients with ER+ and HER2- breast cancer who were treated with adjuvant aromatase inhibitor therapy. The results reveal the importance of combining PgR status with BMI into a single prognostic factor. To our knowledge, this is the first report to demonstrate an association between PgR/BMI status and the outcome of adjuvant aromatase inhibitor therapy for postmenopausal patients with breast cancer.

Three randomized trials in the adjuvant setting of postmenopausal breast cancer have examined the role of BMI in the relative effectiveness of aromatase inhibitors vs. tamoxifen: The Arimidex, Tamoxifen, Alone or in Combination (ATAC) trial (24); the Breast International Group (BIG) 1-98 trial (25); and the Tamoxifen Exemestane Adjuvant Multinational (TEAM) trial (26). In the three trials, an aromatase inhibitor was associated with improved outcomes compared with that of tamoxifen at all BMI values. Notably, BMI did not significantly interact with letrozole (vs. tamoxifen) in the BIG 1-98 trial (25), whereas the ATAC investigators concluded that the relative benefit of anastrozole (vs. tamoxifen) may be more pronounced in women of a lower weight (24). These findings do not support the notion that BMI can predict the benefit of aromatase inhibitors (vs. tamoxifen) as adjuvant therapies in postmenopausal patients with breast cancer (27). Sendur et al (28) reported similar findings from a retrospective analysis. The study showed that the one- and three-year disease-free survival and three-year overall survival rates following treatment with aromatase inhibitors were similar among patients who were overweight, obese and of normal weight. They concluded that BMI does not negatively impact the outcomes of ER+ breast cancer in postmenopausal patients. The current finding that BMI did not reach statistical significance for RFI in multivariate analysis supported those of Sendur et al (28).

A number of studies have identified an association between levels of endogenous sex hormones and BMI in postmenopausal women (29-31). The conversion of androstenedione to estrone or estradiol by aromatase in adipose tissue is a major source of estrogen in postmenopausal women (9-11). A high BMI leads to elevated serum estradiol concentrations. The association between plasma estrogen levels and BMI in postmenopausal women with breast cancer treated with aromatase inhibitors has also been investigated in numerous studies (32-35), however, the results are inconsistent. Among them, the ALIQUOT study (Anastrozole vs. Letrozole, an Investigation of Quality Of Life and Tolerability) identified a relationship between poorly suppressed levels of plasma estradiol and estrone sulfate and a high BMI during treatment with aromatase inhibitors (36). Although the effects of BMI on clinical outcomes and on estrogen levels in postmenopausal women with breast cancer treated with aromatase inhibitors have not yet been clarified, it is clear that a high BMI is not advantageous to the outcome of such treatment.
Meanwhile, the molecular mechanisms of $\mathrm{PgR}$ remain largely unknown. The PgR is synthesized by tumor cells following stimulation by estrogens through interaction with the ER. The ER pathway targets PgR, the presence of which reflects a functional ER pathway $(37,38)$. In theory, PgR may be a better indicator of hormonal dependence. The St. Gallen international expert consensus on primary therapy for early breast cancer 2013 has recently adopted PgR status to define more endocrine-sensitive subgroups (17). The results of the present study showed that PgR- and/or BMI-H when associated with a high Ki-67 labeling index was an independent predictor of a poor prognosis in addition to being a more significant predictor than positive nodal status. Conversely, PgR+ tumors together with BMI-L indicated highly sensitive endocrine tumors and low levels of plasma estrogen, which may be a good indication for therapy with aromatase inhibitors. Combined PgR/BMI status could thus theoretically lead to better outcomes. However, this notion must be addressed by evaluating aromatization and estrogen levels during treatment in future studies.

The limitations of the present study include the small sample cohort, the retrospective design, the single institution and the short follow-up period. Furthermore, baseline values composed the only available information about BMI, which did not reflect weight changes during follow-up. Nonetheless, a clear statistical difference was identified between PgR/BMI statuses. A prospective analysis of $\mathrm{PgR}$ and $\mathrm{BMI}$ is required to assess its role as a biomarker of outcomes among patients with ER+/HER2- breast cancer.

In conclusion, the present retrospective analysis demonstrated that PgR/BMI status may serve as a useful prognostic factor in postmenopausal women with ER+ and HER2- breast cancer treated with adjuvant aromatase inhibitors. PgR and BMI may be an important consideration when customizing adjuvant treatment strategies.

\section{References}

1. Iwase H: Current topics and perspectives on the use of aromatase inhibitors in the treatment of breast cancer. Breast Cancer 15: 278-290, 2008.

2. Burstein HJ, Prestrud AA, Seidenfeld J, Anderson H, Buchholz TA, Davidson NE, Gelmon KE, Giordano SH, Hudis CA, Malin J, et al: American society of clinical oncology clinical practice guideline: Update on adjuvant endocrine therapy for women with hormone receptor-positive breast cancer. J Clin Oncol 28: 3784-3796, 2010.

3. Cardoso F, Harbeck N, Fallowfield L, Kyriakides S and Senkus E; ESMO Guidelines Working Group: Locally recurrent or metastatic breast cancer: ESMO Clinical Practice Guidelines for diagnosis, treatment and follow-up. Ann Oncol 21 (Suppl 7): vii11-vii19, 2012.

4. Dowsett M, Allred C, Knox J, Quinn E, Salter J, Wale C, Cuzick J, Houghton J, Williams N, Mallon E, et al: Relationship between quantitative estrogen and progesterone receptor expression and human epidermal growth factor receptor 2 (HER-2) status with recurrence in the arimidex, tamoxifen, alone or in combination trial. J Clin Oncol 26: 1059-1065, 2008.

5. Viale G, Regan MM, Dell'Orto P, Mastropasqua MG, Maiorano E, Rasmussen BB, MacGrogan G, Forbes JF, Paridaens RJ, Colleoni M, et al: Which patients benefit most from adjuvant aromatase inhibitors? Results using a composite measure of prognostic risk in the BIG 1-98 randomized trial. Ann Oncol 22: 2201-2207, 2011.

6. Bartlett JM, Brookes CL, Robson T, van de Velde CJ, Billingham LJ, Campbell FM, Grant M, Hasenburg A, Hille ET, Kay $\mathrm{C}$, et al: Estrogen receptor and progesterone receptor as predictive biomarkers of response to endocrine therapy: A prospectively powered pathology study in the tamoxifen and exemestane adjuvant multinational trial. J Clin Oncol 29: 1531-1538, 2011. 
7. Horwitz KB and McGuire WL: Oestrogen control of progesterone receptor in human breast cancer: correlation with nuclear processing of oestrogen receptor. J Biol Chem 253: 2223-2228, 1978.

8. Dowsett M, Houghton J, Iden C, Salter J, Farndon J, A'Hern R, Sainsbury R and Baum M: Benefit from adjuvant tamoxifen therapy in primary breast cancer patients according oestrogen receptor, progesterone receptor, EGF receptor and HER2 status. Ann Oncol 17: 818-826, 2006.

9. Yamashita H, Iwase H, Toyama T, Takahashi S, Sugiura H, Yoshimoto N, Endo Y, Fujii Y and Kobayashi S: Estrogen receptor-positive breast cancer in Japanese women: Trends in incidence, characteristics and prognosis. Ann Oncol 22: 1318-1325, 2011.

10. Berclaz G, Li S, Price KN, Coates AS, Castiglione-Gertsch M, Rudenstam CM, Holmberg SB, Lindtner J, Erien D, Collins J, et al: Body mass index as a prognostic feature in operable breast cancer: The international breast cancer study group experience. Ann Oncol 15: 875-884, 2004

11. Elliot KM, Dent J, Stanczyk FZ, Woodley L, Coombes RC, Purohit A and Palmieri C: Effects of aromatase inhibitors and body mass index on steroid hormone levels in women with early and advanced breast cancer. Br J Surg 101: 939-948, 2014.

12. Slamon DJ, Leyland-Jones B, Shak S, Fuchs H, Paton V, Bajamonde A, Fleming T, Eiermann W, Wolter J, Pegram M, et al: Use of chemotherapy plus a monoclonal antibody against HER2 for metastatic breast cancer that overexpresses HER2. N Engl J Med 344: 783-792, 2001.

13. Goldhirsch A, Glick JH, Gelber RD, Coates AS, Thürlimann B and Senn HJ; Panel members: Meeting highlights: International expert consensus on the primary therapy of early breast cancer 2005. Ann Oncol 16: 1569-1583, 2005.

14. Goldhirsch A, Wood WC, Gelber RD, Coates AS, Thürlimann B and Senn HJ; 10th St. Gallen conference: Progress and promise: Highlights of the international expert consensus on the primary therapy of early breast cancer 2007. Ann Oncol 18: $1133-1144,2007$.

15. Goldhirsch A, Ingle JN, Gelber RD, Coates AS, Thürlimann B and Senn HJ; Panel members: Thresholds for therapies: Highlights of the St Gallen international expert consensus on the primary therapy of early breast cancer 2009. Ann Oncol 20: 1319-1329, 2009

16. Goldhirsch A, Wood WC, Coates AS, Gelber RD, Thürlimann B and Senn HJ; Panel members: Strategies for subtypes-dealing with the diversity of breast cancer: Highlights of the St. Gallen International expert consensus on the primary therapy of early breast cancer 2011. Ann Oncol 22: 1736-1747, 2011.

17. Goldhirsch A, Winer EP, Coates AS, Gelber RD, Piccart-Gebhart M, Thürlimann B and Senn HJ; Panel members: Personalizing the treatment of women with early breast cancer: Highlights of the St Gallen international expert consensus on the primary therapy of early breast cancer 2013 . Ann Oncol 24 2206-2223, 2013

18. National Comprehensive Cancer Network: NCCN Guidelines - Breast Cancer. http://www.nccn.org/professionals/physician_ gls/f_guidelines.asp. Accessed 1st April 2012.

19. WHO Expert Consultation: Appropriate body-mass index for Asian populations and its implications for policy and intervention strategies. Lancet 363: 157-163, 2004.

20. The Japanese Breast Cancer Society: General rules for clinical and pathological recording of breast cancer, 16th ed. Kanehara, Tokyo, 2008

21. Allred DC, Harvey JM, Berardo M and Clark GM: Prognostic and predictive factors in breast cancer by immunohistochemical analysis. Mod Pathol 11: 155-168, 1998

22. Kai K, Nishimura R, Arima N, Miyayama H and Iwase H: p53 expression status is a significant molecular marker in predicting the time to endocrine therapy failure in recurrent breast cancer: A cohort study. Int J Clin Oncol 11: 426-433, 2006.

23. Ohara M, Shigematsu H, Tsutani Y, Emi A, Masumoto N, Ozaki S, Kadoya T and Okada M: Role of FDG-PET/CT in evaluating surgical outcomes of operable breast cancer-usefulness for malignant grade of triple-negative breast cancer. Breast 22: 958-963, 2013
24. Sestak I, Distler W, Forbes JF, Dowsett M, Howell A and Cuzick J: Effect of body mass index on recurrences in tamoxifen and anastrozole treated women: An exploratory analysis from the ATAC trial. J Clin Oncol 28: 3411-3415, 2010.

25. Ewertz M, Gray KP, Regan MM, Ejlertsen B, Price KN, Thürlimann B, Bonnefoi $\mathrm{H}$, Forbes JF, Paridaens RJ, Rabaglio M, et al: Obesity and risk of recurrence or death after adjuvant endocrine therapy with letrozole or tamoxifen in the breast international group 1-98 trial. J Clin Oncol 30: 3967-3975, 2012.

26. Seynaeve C, Hille E, Hasenburg A, Rea D, Markopoulos C, Hozumi Y, Putter H, Nortier H, van Nes J, Dirix L and van de Velde C: Impact of body mass index (BMI) on the efficacy of adjuvant endocrine therapy in postmenopausal hormone sensitive breast cancer (BC) patients; Exploratory analysis from the TEAM study. Cancer Res 70: Abstract S2-S3, 2010.

27. Goodwin PJ: Obesity and endocrine therapy: Host factors and breast cancer outcome. Breast 22 (Suppl 2): S44-S47, 2013

28. Sendur MA, Aksoy S, Zengin N and Altundag K: Efficacy of adjuvant aromatase inhibitor in hormone receptor-positive postmenopausal breast cancer patients according to the body mass index. Br J Cancer 107: 1815-1819, 2012.

29. Hankinson SE, Willett WC, Manson JE, Hunter DJ, Colditz GA, Stampfer MJ, Longcope C and Speizer FE: Alcohol, height and adiposity in relation to estrogen and prolactin levels in postmenopausal women. J Natl Cancer Inst 87: 1297-1302, 1995

30. Mahabir S, Baer DJ, Johnson LL, Hartman TJ, Dorgan JF, Campbell WS, Clevidence BA and Taylor PR: Usefulness of body mass index as a sufficient adiposity measurement for sex hormone concentration associations in postmenopausal women. Cancer Epidemiol Biomarkers Prev 15: 2502-2507, 2006.

31. McTiernan A, Rajan KB, Tworoger SS, Irwin M, Bernstein L, Baumgartner R, Gilliland F, Stanczyk FZ, Yasui Y and Ballard-Barbash R: Adiposity and sex hormones in postmenopausal breast cancer survivors. J Clin Oncol 21: 1961-1966, 2003.

32. Folkerd EJ, Dixon JM, Renshaw L, A'Hern RP and Dowsett M: Suppression of plasma estrogen levels by letrozole and anastrozole is related to body mass index in patients with breast cancer. J Clin Oncol 30: 2977-2980, 2012.

33. Pfeiler G, Königsberg R, Hadji P, Fitzal F, Maroske M, Dressel-Ban G, Zellinger J, Exner R, Seifert M, Singer C, et al: Impact of body mass index on estradiol depletion by aromatase inhibitors in postmenopausal women with early breast cancer. $\mathrm{Br}$ J Cancer 109: 1522-1527, 2013.

34. Sini V, Lunardi G, Cirillo M, Turazza M, Bighin C, Giraudi S, Levaggi A, Piccioli P, Bisagni G, Gnoni R, et al: Body mass index and circulating oestrone sulphate in women treated with adjuvant letrozole. Br J Cancer 110: 1133-1138, 2014.

35. Lønning PE, Haynes BP and Dowsett M: Relationship of body mass index with aromatisation and plasma and tissue oestrogen levels in postmenopausal breast cancer patients treated with aromatase inhibitors. Eur J Cancer 50: 1055-1064, 2014.

36. Folkerd EJ, Dixon JM, Renshaw L, A'Hern RP and Dowsett M Suppression of plasma estrogen levels by letrozole and anastrozole is related to body mass index in patients with breast cancer. J Clin Oncol 30: 2977-2988, 2012.

37. Arafah BM, Finegan HM, Roe J, Manni A and Pearson OH: Hormone dependency in N-nitrosomethylurea-induced rat mammary tumors. Endocrinology 111: 584-588, 1982.

38. Brisken C: Progesterone signalling in breast cancer: A neglected hormone coming into the limelight. Nat Rev Cancer 13: 385-396, 2013. 